\title{
A ATIVIDADE ORIENTADORA DE ENSINO COMO PRESSUPOSTO TEÓRICO-METODOLÓGICO DE PESQUISAS
}

\author{
Maria Lucia Panossian ${ }^{1}$ \\ Fabiana Fiorezi de Marco $^{2}$ \\ Anemari Roesler Luersen Vieira Lopes $^{3}$ \\ Flávia Dias de Souza ${ }^{4}$ \\ Vanessa Dias Moretti ${ }^{5}$
}

\section{Resumo}

O objetivo deste artigo é analisar a Atividade Orientadora de Ensino (AOE) no desenvolvimento de pesquisas em espaços formativos que tiveram como foco o professor que ensina matemática. Foram selecionadas quatorze pesquisas desenvolvidas no período de 2007 a 2016, no âmbito do Grupo de Estudos e Pesquisa sobre Atividade Pedagógica. O texto discute o conceito de AOE, seus elementos e os fundamentos teóricos que o sustentam buscando reconhecer sua presença na metodologia das pesquisas analisadas no processo de produção e análise de dados. As análises revelam que ainda que todas as pesquisas foram sido realizadas em espaços formativos onde estiveram vigentes os princípios da AOE, e que em algumas delas os espaços foram intencionalmente organizados para a produção dos dados. Além disso,

\footnotetext{
${ }^{1}$ Doutora em Educação (USP). Professora do Magistério Superior na Universidade Tecnológica Federal do Paraná (UTFPR). Pesquisadora dos grupos GEPAPe (USP) e GeforProf (UTFPR). Docente do Programa de PósGraduação PPGFCET (UTFPR) e PPGECM (UFPR). E-mail: malupanossian@ hotmail.com

2 Pós-doutora em Educação (USP). Docente adjunto nível 4 (DE) na Faculdade de Matemática- FAMAT/UFU. Pesquisadora do grupo GEPAPe (USP), coordenadora e pesquisadora do grupo GEPEMAPe (UFU). Docente do Programa de Pós-Graduação PPGECM (UFU) e PPGED (UFU). E-mail: fabiana.marco@ufu.br

${ }^{3}$ Pós-doutora em Educação (USP). Docente adjunto do Centro de Educação da Universidade Federal de Santa Maria (UFSM). Pesquisadora do grupo GEPAPe (USP), coordenadora e pesquisadora do grupo GEPEMat (UFSM). Docente do Programa de Pós-Graduação em Educação (PPGE/UFSM) e do Programa de Pós-Graduação em Educação Matemática e Ensino de Física (PPGEM\&EF). E-mail: anemari.lopes@gmail.com

${ }^{4}$ Doutora em Educação (USP). Professora Adjunta na Universidade Tecnológica Federal do Paraná (UTFPR). Pesquisadora dos grupos GEPAPe (USP) e docente do Programa de Pós-Graduação PPGECM/UFPR. E-mail: flaviad@utfpr.edu.br

${ }^{5}$ Pós-doutora em Educação. Professora Adjunto da Universidade Federal de São Paulo (UNIFESP). Pesquisadora do grupo GEPAPe (USP) e líder do GEPPEDH (UNIFESP). Docente do programa de pós-graduação em Educação (PPGE- UNIFESP) e do Programa de pós-graduação em Educação (PPGE- FEUSP). E-mail: vanessadmoretti@gmail.com
} 
identificaram-se pesquisas em que os elementos da AOE fundamentaram os processos de análise ou de forma mais específica possibilitaram a construção de categorias ou unidades de análise dos dados da pesquisa.

Palavras-chave: Atividade Orientadora de Ensino; Professores que ensinam matemática; Metodologia de pesquisa; Teoria histórico-cultural

\title{
THE TEACHING-ORIENTEERING ACTIVITY AS THEORETICAL- METHODOLOGICAL BACKGROUND OF RESEARCH
}

\begin{abstract}
This paper aims to analyze the Teaching-Orienteering Activity (AOE) in the development of researches built in education spaces and then focused on the teacher who teaches mathematics. We selected fourteen researches developed in the period from 2007 to 2016, within the framework of the Group of Studies and Research on Pedagogical Activity. The text discusses the concept of AOE, its elements and the theoretical foundations to looking for its presence in the methodology of the analyzed researches, considering their production process and data analysis. The analyses revealed that all the researches were carried out in education spaces where the principles of the AOE were present, however, some of these spaces were intentionally organized for the production of the data. Regarding the data analysis process, researches were identified in which the AOE and its elements underpinned the analysis process and made it possible to construct categories or units of analysis.
\end{abstract}

Key-words: Teaching-Orienteering Activity; Teachers who teach mathematics; Research Methodology; Historical-cultural theory 


\title{
LA ACTIVIDAD ORIENTADORA DE ENSEÑANZA COMO PRESUPUESTO TEÓRICO-METODOLÓGICO DE INVESTIGACIONES
}

\begin{abstract}
Resumen
Este artículo pretende analizar la Actividad Orientadora de Enseñanza (AOE) en el desarrollo de investigaciones realizadas en espacios formativos con foco en el profesor que enseña matemáticas. Se seleccionaron catorce investigaciones desarrolladas en el período de 2007 a 2016, en el ámbito del Grupo de Estudios e Investigación sobre Actividad Pedagógica. El texto discute el concepto de AOE, sus elementos y fundamentos teóricos para reconocer su presencia en la metodología de las investigaciones analizadas, en el proceso de producción y análisis de datos. Los análisis revelan que, aunque todas las investigaciones se realizaron en espacios formativos donde estuvieron vigentes principios de la AOE, en algunas de ellas los espacios fueron intencionalmente organizados para producción de datos. Además, se identificaron investigaciones en que la AOE y sus elementos fundamentaron los análisis, o de forma específica posibilitaran la construcción de categorías o unidades de análisis de datos.
\end{abstract}

Palabras clave: Actividad Orientadora de Enseñanza; Profesores que enseñan matemáticas; Metodología de investigación; Teoría histórico-cultural

\section{INTRODUÇÃo}

A busca pela satisfação de suas necessidades levou o ser humano a criar soluções que o conduziram à observação e ao estudo dos fenômenos. Sua atividade, tanto individual quanto social, sempre exigiu um conhecimento do mundo que o cercava. Mas só conhecer os fenômenos não é suficiente para dominá-los. Faz-se necessário determinar as razões de sua existência, suas relações e os aspectos intrínsecos de sua manifestação. Nisso consiste, como bem coloca Caraça (1989), a investigação dos "comos?" e dos "por quês?" que distinguem fundamentalmente a atividade humana das de outros animais. É a produção do conhecimento 
que lhe permite dominar a natureza e imprimir-lhe uma dimensão humana. Ou seja, pelo conhecimento, o sujeito se apropria da produção cultural humana.

Conforme Molon (2008), compreende-se a pesquisa como uma atividade humana que é mediada socialmente e que

visa à criação de um novo conhecimento, produzido e apropriado com inventividade e rigor científico, que implica necessariamente a transformação de algo, quer seja nos sujeitos envolvidos direta e indiretamente, quer seja nos objetos de estudo pesquisados. (p. 57).

Mas a concretização de uma pesquisa nessa perspectiva exige que a mesma se paute em conhecimentos que fundamentem o seu desenvolvimento. Além disso, deve advir de uma concepção sobre as possíveis contribuições do conhecimento produzido. E é a dimensão de uma tomada de consciência sobre a relevância da pesquisa que possibilita a objetivação de ações e a produção de conhecimento científico que leva o Grupo de Estudos e Pesquisas sobre a Atividade Pedagógica (GEPAPe) a buscar na Teoria Histórico-Cultural, na Teoria da Atividade e, mais especificamente, na Atividade Orientadora de Ensino - AOE (MOURA, 1996, 2001, 2010), fundamentos teóricos e metodológicos para desenvolver suas investigações na área da Educação.

Frente a estes referenciais teóricos, entende-se que o objeto da pesquisa em Educação centra-se nos processos relativos às ações que visam aprofundar os conhecimentos sobre a atividade pedagógica e sobre o seu impacto nos processos de formação dos sujeitos que a concretizam. Isso implica em analisar os diferentes fenômenos que envolvem o processo de ensino e de aprendizagem: o ensino como atividade de trabalho para o professor e o aprender como objeto da atividade de estudo do aluno. Assim, a pesquisa educacional, neste contexto teórico, pode assumir diferentes dimensões, sendo que o que instigou a escrita deste artigo foi a busca da compreensão do seguinte problema: quais as contribuições da AOE para o desenvolvimento de pesquisas em espaços formativos que tem como foco o professor que ensina matemática?

Esta questão deriva dos estudos e pesquisas de membros do GEPAPe, que reúne pesquisadores de diferentes regiões do Brasil, com interesse voltado à atividade pedagógica, segundo os princípios teórico-metodológicos da abordagem histórico-cultural. Para tanto, o olhar foi lançado para as investigações desenvolvidas no âmbito desse grupo nos últimos dez 
anos, com o objetivo de analisar o papel da AOE no desenvolvimento de pesquisas em espaços formativos que tem como foco o professor que ensina matemática.

Com o intuito de situar o leitor acerca do embasamento teórico, o texto estrutura-se com uma discussão inicial sobre o conceito de Atividade Orientadora de Ensino. Posteriormente apresenta os encaminhamentos metodológicos adotados e os dados produzidos, bem como as análises realizadas.

\section{FUNDAMENTAÇÃO TEÓRICA: A ATIVIDADE ORIENTADORA DE ENSINO}

O elemento teórico que será analisado nas dissertações e teses definidas nesta investigação é a Atividade Orientadora de Ensino (AOE). Assim, serão apresentados seus elementos e os fundamentos teóricos que o sustentam.

O conceito de AOE foi elaborado por Manoel Oriosvaldo de Moura em 1992 e, desde então, tem se desenvolvido nos trabalhos deste autor e, posteriormente, de seus orientandos, pesquisadores do Grupo de Estudos e Pesquisas sobre Atividade Pedagógica (GEPAPe), possibilitando a estruturação tanto do ensino quanto da pesquisa. A maioria desses trabalhos está articulada com a Educação Matemática, mas já existem pesquisas articulando este conceito teórico a outras áreas do conhecimento.

Os primeiros registros sobre a AOE (MOURA, 1992) indicam o quanto a sua estruturação está associada à apropriação dos conceitos pelos sujeitos. O autor define que “[...] a estrutura da atividade orientadora é a própria gênese do conceito: o problema desencadeador, a busca de ferramentas intelectuais para solucioná-lo, o surgimento das primeiras soluções e a busca de otimização destas soluções” (MOURA, 1992, p. 68).

Assim, a AOE se concretiza a partir da organização de um problema desencadeador para o estudante que propicie a apropriação do conceito, organizado na forma de uma história virtual, de um jogo, de uma situação contextualizada ou do cotidiano (MOURA, 1992). A elaboração do problema desencadeador fundamenta-se na unidade entre o lógico e o histórico do conceito (LANNER DE MOURA; SOUSA, 2005), compreendida no movimento social e cultural de desenvolvimento de um conceito e, como explicita Cedro (2008, p. 60), “(...) compreender a gênese do conceito significa perceber que ela faz parte da história, na qual os homens e as mulheres, perante as necessidades objetivas, buscaram e elaboram soluções para determinados problemas". 
Denomina-se orientadora no sentido que possibilita sistematizar os elementos da organização do ensino. É importante observar que as primeiras produções sobre o conceito de $\mathrm{AOE}^{6}$ têm como foco as ações e operações do professor relacionadas à organização do ensino e as ações e operações dos estudantes para a apropriação de um conceito.

A proposição da AOE e de seus elementos característicos "permitem que ela seja elemento de mediação entre a atividade de ensino e a atividade de aprendizagem" (MOURA et al, 2010, p. 100), onde o motivo de ambas deve coincidir para que sejam concretizadas. $\mathrm{Na}$ estruturação dos fundamentos da AOE, Moura $(1996,2001,2010)$ parte da Teoria da Atividade, proposta por Leontiev (1978, 1983, 2001), que define atividade como "os processos psicologicamente caracterizados por aquilo a que o processo, como um todo, se dirige (seu objeto), coincidindo sempre com o objetivo que estimula o sujeito a executar esta atividade, isto é, o motivo" (LEONTIEV, 2001, p. 68).

Segundo Leontiev (1978), para que uma situação se caracterize como uma atividade é necessário que ela compreenda: o objeto, o motivo, a operação/ação, a consciência e o objetivo. Nesse sentido, a AOE pode ser definida como aquela que

mantém a estrutura da atividade proposta por Leontiev, ao indicar uma necessidade (apropriação da cultura), um motivo real (apropriação do conhecimento historicamente acumulado), objetivos (ensinar e aprender) e propor ações que considerem as condições objetivas da instituição escolar. (MOURA et al, 2010, p. 96).

Assim, a AOE se estrutura considerando que a atividade é a unidade de análise do psiquismo humano (LEONTIEV, 1983) e que em atividade o sujeito se desenvolve, sendo que por meio dela se pode reconhecer não só o desenvolvimento do estudante, mas também a formação e o desenvolvimento do professor. Neste sentido, Moura (1996) evidencia como importante no desenvolvimento de uma atividade de ensino um "novo" olhar do professor sobre o significado de ensinar e aprender, nas relações de sala de aula. $\mathrm{O}$ autor ainda defende que a

atividade de ensino deve conter em si a formação do professor que toma o ato de educar como uma situação-problema, já que esta possui o elemento humanizador do professor: a capacidade de avaliar as suas ações e poder decidir por novas ferramentas e novas estratégias na concretização de seus objetivos. (MOURA, 1996, p. 36). 
Em outro trabalho, Moura (2000) pontua que a necessidade é elemento indispensável para que haja o desencadeamento dos processos de formação de professores, pois ao construir uma atividade com intencionalidade, o professor "opta por conteúdos que tenham potencialidade de impacto na formação do aluno" (MOURA, 2000, p. 118).

Pode-se considerar que, na formação de professores, a AOE é

um instrumento teórico-metodológico e quando isto acontece pode ser orientadora da formação docente, pois a organização e desenvolvimento da proposta elaborada possibilita a todos os envolvidos aprofundarem seus conhecimentos, sejam eles teóricos (professores e estudantes) ou metodológicos (pesquisador). (MARCO; MOURA, 2016, p. 24).

Diante de todo o exposto, se reconhece por meio de Moraes (2008) as principais características da AOE como base teórico-metodológica para a organização do ensino:

- a intencionalidade pedagógica;

- a situação desencadeadora de aprendizagem é a materialização da atividade de ensino;

- a essência do conceito;

- a mediação é condição fundamental para o desenvolvimento da atividade;

- a necessidade do trabalho coletivo;

- torna-se uma atividade do sujeito (MORAES, 2008, p. 232).

\section{AÇÕES METODOLÓGICAS E DESCRIÇÃO DOS DADOS}

Definiu-se como recorte para este artigo as pesquisas realizadas no âmbito do Grupo de Estudos e Pesquisa sobre Atividade Pedagógica (GEPAPe), coordenado pelo Prof. Dr. Manoel Oriosvaldo de Moura, que investiga a atividade pedagógica segundo os pressupostos da Teoria Histórico-Cultural e da Teoria da Atividade. Foram selecionadas pesquisas desenvolvidas no período de 2007 a 2016 e que se referem à Atividade Orientadora de Ensino (AOE), tendo como foco o professor que ensina matemática em espaços formativos (Clube de Matemática, Oficina Pedagógica de Matemática, disciplinas de cursos de licenciatura, cursos de extensão elaborados para pesquisa, Projeto Observatório da Educação etc).

Atendendo a esses critérios foram identificadas quatro dissertações (BARROS, 2007; SILVA, 2008; RITZMANN, 2009; VACCAS, 2012) e dez teses (MORAES, 2008; FURLANETO, 2013; DIAS, 2007; MIGUÉIS, 2010; MORETTI, 2007; CEDRO, 2008; RIBEIRO, 2011; PANOSSIAN, 2013; GLADCHEFF, 2015; ARAÚJO, 2015). 
Quadro 1: Pesquisas selecionadas para análise: objetivos, sujeitos e contextos

\begin{tabular}{|c|c|c|c|}
\hline AUTOR & OBJETIVO & SUJEITOS & CONTEXTO \\
\hline $\begin{array}{l}\text { MORAES, } \\
2008 \\
\text { (Tese) }\end{array}$ & $\begin{array}{l}\text { Investigar o significado da avaliação em } \\
\text { matemática na perspectiva histórico- } \\
\text { cultural, focalizando a teoria da } \\
\text { atividade. }\end{array}$ & $\begin{array}{c}\text { Professoras das } \\
\text { séries iniciais rede } \\
\text { pública de Ribeirão } \\
\text { Preto. }\end{array}$ & $\begin{array}{l}\text { Oficina Pedagógica de } \\
\text { matemática }\end{array}$ \\
\hline $\begin{array}{l}\text { BARROS, } \\
2007 \\
\text { (Dissertação) } \\
\end{array}$ & $\begin{array}{l}\text { Investigar como se desenvolve o } \\
\text { conceito de avaliação na formação de } \\
\text { professores em atividade colaborativa. }\end{array}$ & $\begin{array}{c}\text { Estudantes do curso } \\
\text { de Pedagogia. }\end{array}$ & \multirow{4}{*}{$\begin{array}{l}\text { Clube de Matemática, } \\
\text { projeto de estágio }\end{array}$} \\
\hline $\begin{array}{l}\text { RITZMANN, } \\
2009 \\
\text { (Dissertação) }\end{array}$ & $\begin{array}{l}\text { Analisar como ocorre o desenvolvimento } \\
\text { da compreensão do jogo na atividade de } \\
\text { ensino para professores em formação } \\
\text { inicial. }\end{array}$ & $\begin{array}{l}\text { Estudantes de } \\
\text { Licenciatura em } \\
\text { Matemática e } \\
\text { Pedagogia. } \\
\end{array}$ & \\
\hline $\begin{array}{l}\text { VACCAS, } \\
2012 \\
\text { (Dissertação) }\end{array}$ & $\begin{array}{l}\text { Investigar o processo de significação do } \\
\text { planejamento como ação da atividade } \\
\text { pedagógica. }\end{array}$ & $\begin{array}{l}\text { Estudantes dos } \\
\text { cursos de } \\
\text { Licenciatura em } \\
\text { Matemática e } \\
\text { Pedagogia. } \\
\end{array}$ & \\
\hline $\begin{array}{l}\text { FURLANETTO, } \\
2013 \\
\text { (Tese) }\end{array}$ & $\begin{array}{l}\text { Investigar o movimento de mudança de } \\
\text { sentido pessoal do futuro educador diante } \\
\text { da necessidade de organizar a atividade } \\
\text { de ensino. }\end{array}$ & $\begin{array}{l}\text { Estudantes do curso } \\
\text { de Pedagogia. }\end{array}$ & \\
\hline $\begin{array}{l}\text { SILVA, } 2008 \\
\text { (Dissertação) }\end{array}$ & $\begin{array}{l}\text { Investigar determinantes e indicadores } \\
\text { constitutivos de processos de } \\
\text { aprendizagem de professores com } \\
\text { objetivo de elaborar atividades de ensino } \\
\text { de matemática para educação infantil. }\end{array}$ & $\begin{array}{l}\text { Educadores da rede } \\
\text { pública do } \\
\text { município de São } \\
\text { Paulo. }\end{array}$ & \multirow{4}{*}{$\begin{array}{l}\text { Curso de atualização } \\
\text { para professores da } \\
\text { rede pública }\end{array}$} \\
\hline $\begin{array}{l}\text { PANOSSIAN } \\
2013 \\
\text { (Tese) }\end{array}$ & $\begin{array}{l}\text { Investigar as relações entre o movimento } \\
\text { histórico e lógico dos conceitos } \\
\text { algébricos e o objeto de ensino da álgebra } \\
\text { revelado em propostas curriculares e nas } \\
\text { ações dos professores a partir dos } \\
\text { princípios da teoria histórico-cultural e } \\
\text { da teoria da atividade. }\end{array}$ & $\begin{array}{l}\text { Professores da rede } \\
\text { pública que } \\
\text { participaram de } \\
\text { curso de extensão }\end{array}$ & \\
\hline $\begin{array}{l}\text { MORETTI, } \\
2007 \\
\text { (Tese) }\end{array}$ & $\begin{array}{l}\text { Investigar o processo de formação de } \\
\text { professores em atividades de ensino, ao } \\
\text { elaborarem coletivamente situações } \\
\text { desencadeadoras de aprendizagem. }\end{array}$ & $\begin{array}{l}\text { Grupo de } \\
\text { professores de } \\
\text { escolas públicas }\end{array}$ & \\
\hline $\begin{array}{l}\text { DIAS, } 2007 \\
\quad \text { (Tese) }\end{array}$ & $\begin{array}{l}\text { Compreender o processo de formação da } \\
\text { imagem conceitual da reta real em } \\
\text { relação com o desenvolvimento desse } \\
\text { conceito na perspectiva lógico-histórica, } \\
\text { na interação indivíduo-coletividade. }\end{array}$ & $\begin{array}{l}\text { Professores da rede } \\
\text { pública do estado de } \\
\text { São Paulo }\end{array}$ & \\
\hline $\begin{array}{l}\text { MIGUEIS, } \\
2010 \\
\text { (Tese) }\end{array}$ & $\begin{array}{l}\text { Dinamizar a formação de professores, } \\
\text { constituindo-se como desencadeador e } \\
\text { organizador de atividades de ensino, } \\
\text { sistematizador do conhecimento } \\
\text { matemático e problematizador das } \\
\text { práticas docentes. }\end{array}$ & $\begin{array}{l}\text { Educadoras de } \\
\text { jardins de infância } \\
\text { de Aveiro e São } \\
\text { João da Madeira. }\end{array}$ & $\begin{array}{l}\text { Projeto de } \\
\text { formação/investigação } \\
\text { com educadoras de } \\
\text { infância }\end{array}$ \\
\hline
\end{tabular}




\begin{tabular}{|c|c|c|c|}
\hline $\begin{array}{l}\text { CEDRO, } \\
2008 \\
\text { (Tese) }\end{array}$ & $\begin{array}{l}\text { Discutir o processo de transformação } \\
\text { e/ou criação dos motivos na atividade de } \\
\text { aprendizagem dos futuros licenciados em } \\
\text { Matemática durante o desenvolvimento } \\
\text { do estágio supervisionado. }\end{array}$ & $\begin{array}{l}\text { Estudantes de } \\
\text { licenciatura em } \\
\text { Matemática. }\end{array}$ & $\begin{array}{l}\text { Disciplinas } \\
\text { relacionadas ao } \\
\text { Estágio }\end{array}$ \\
\hline $\begin{array}{l}\text { RIBEIRO, } \\
2011 \\
\text { (Tese) }\end{array}$ & $\begin{array}{l}\text { Investigou a apropriação de elementos } \\
\text { constitutivos de um modo geral de } \\
\text { organização do ensino por futuros } \\
\text { professores de Matemática. }\end{array}$ & $\begin{array}{l}\text { Estudantes de } \\
\text { licenciatura em } \\
\text { Matemática. }\end{array}$ & Supervisionado \\
\hline $\begin{array}{l}\text { GLADCHEFF, } \\
2015 \\
\text { (Tese) }\end{array}$ & $\begin{array}{l}\text { Investigar o processo de significação da } \\
\text { atividade de ensino evidenciado pelas } \\
\text { ações dos professores para concretização } \\
\text { da atividade de formação para, assim, } \\
\text { identificar ações potenciais } \\
\text { desencadeadoras de tal processo. }\end{array}$ & \multirow{2}{*}{$\begin{array}{c}\text { Professores e } \\
\text { coordenadores } \\
\text { pedagógicos de } \\
\text { escolas públicas que } \\
\text { participaram de uma } \\
\text { atividade de } \\
\text { formação integrada } \\
\text { ao Programa. }\end{array}$} & \multirow{2}{*}{$\begin{array}{l}\text { Projeto Observatório } \\
\text { da Educação } \\
\text { (OBEDUC), da } \\
\text { CAPES }\end{array}$} \\
\hline $\begin{array}{l}\text { ARAÚJO, } \\
2015 \\
\text { (Tese) }\end{array}$ & $\begin{array}{l}\text { Investigar o processo de apropriação de } \\
\text { conceitos matemáticos por professores } \\
\text { do Ensino Fundamental em atividade de } \\
\text { aprendizagem, em que se deu destaque } \\
\text { ao conceito de medida. }\end{array}$ & & \\
\hline
\end{tabular}

Fonte: dados dos autores

Definidas as pesquisas a serem analisadas, caracterizando-as conforme o seu objetivo e contexto de investigação, iniciou-se o processo de análise. Para tanto, já tendo identificado que todas as pesquisas incorporavam o conceito de AOE em sua fundamentação teórica, investigouse quais foram as referências teóricas adotadas para fundamentar tal conceito e de que forma este foi reconhecido no movimento da pesquisa, ou seja, em relação à organização metodológica (implicando na produção de dados) e em relação à organização e fundamentação das análises. A discussão e os resultados dessas análises serão apresentados no próximo item.

\section{ANÁLISES REALIZADAS}

O processo de análise buscou identificar as principais obras de Moura utilizadas como fundamento teórico para a pesquisa, o modo como as pesquisas pautaram-se na AOE em relação aos procedimentos metodológicos no processo de produção de dados (AOE como elemento da metodologia de pesquisa) e ao processo de análise dos dados (AOE como elemento de análise).

Foi possível identificar que todas as pesquisas analisadas possuíam ações investigativas e formativas. E, ainda que todas tenham sido realizadas em espaços formativos onde estivessem 
vigentes os princípios da $\mathrm{AOE}$, algumas delas organizaram estes espaços de modo intencional para a produção dos dados e, assim, seu objetivo esteve relacionado ao de organização do espaço formativo. Assim, a coluna "produção dos dados" identifica se o pesquisador recorreu aos princípios da AOE para organização do espaço formativo onde seriam produzidos os dados. Já na coluna "análise dos dados" buscou-se identificar como a AOE possibilitou a análise dos dados, seja na construção das categorias ou unidades de análise, ou buscando reconhecer elementos da AOE durante os processos de análise.

Quadro 2: Referências teóricas e a AOE nas pesquisas selecionadas

\begin{tabular}{|c|c|c|c|}
\hline \multirow{2}{*}{$\begin{array}{l}\text { AUTOR DA } \\
\text { PESQUISA }\end{array}$} & \multirow{2}{*}{$\begin{array}{c}\text { AUTORES/TEXTOS DE } \\
\text { REFERENCIA (AOE) }\end{array}$} & \multicolumn{2}{|c|}{ AOE } \\
\hline & & Produção de dados & Análise dos dados \\
\hline BARROS, 2007 & MOURA, 1996, 1998, 2001 & \multirow{8}{*}{$\begin{array}{c}\text { Espaço formativo já } \\
\text { organizado }\end{array}$} & $\begin{array}{ll}------ \\
\end{array}$ \\
\hline VACCAS, 2012 & MOURA, 1996, 2002, 2010 & & ------- \\
\hline $\begin{array}{l}\text { FURLANETTO, } \\
2013\end{array}$ & MOURA, 1996,1996a, 2002 & & ------- \\
\hline CEDRO, 2008 & $\begin{array}{l}\text { MOURA, 1992, 1996, 1999, } \\
2000,2001,2002,2003,2004\end{array}$ & & \multirow[b]{2}{*}{$\begin{array}{c}\text { Recorre aos elementos } \\
\text { da AOE para análise }\end{array}$} \\
\hline RIBEIRO, 2011 & $\begin{array}{l}\text { MOURA, 1993, 1998, 1999, } \\
\text { 2002, 2003, 2004 } \\
\text { MOURA et al., } 2010\end{array}$ & & \\
\hline $\begin{array}{l}\text { GLADCHEFF, } \\
2015\end{array}$ & $\begin{array}{l}\text { MOURA, 1996, 2004, } 2012 \\
\text { MOURA et al., } 2010\end{array}$ & & \multirow{3}{*}{$\begin{array}{c}\text { Constrói categorias a } \\
\text { partir dos elementos da } \\
\text { AOE }\end{array}$} \\
\hline ARAÚJO, 2015 & $\begin{array}{l}\text { MOURA, 1996, 2001, } \\
\text { MOURA et al., } 2010\end{array}$ & & \\
\hline $\begin{array}{l}\text { RITZMANN, } \\
2009\end{array}$ & MOURA, 1996, 2001 & & \\
\hline MIGUEIS, 2010 & $\begin{array}{l}\text { MOURA, 1996, } 2001 \\
\text { LANNER DE MOURA e } \\
\text { MOURA, } 1996\end{array}$ & \multirow{6}{*}{$\begin{array}{l}\text { Espaço formativo } \\
\text { organizado pelo } \\
\text { pesquisador }\end{array}$} & \multirow{4}{*}{$\begin{array}{l}\text { Recorre aos elementos } \\
\text { da AOE para análise }\end{array}$} \\
\hline $\begin{array}{l}\text { PANOSSIAN, } \\
2013 \\
\end{array}$ & MOURA, 1996, 2001, 2010 & & \\
\hline MORETTI, 2007 & MOURA, 1992,1996, 2001 & & \\
\hline MORAES, 2008 & $\begin{array}{l}\text { MOURA, 1992, 1996, 1996a, } \\
1998,2000,2001,2003\end{array}$ & & \\
\hline SILEM, 2008 & MOURA, 1996, 2000, 2001 & & \multirow{2}{*}{$\begin{array}{l}\text { Constrói categorias a } \\
\text { partir dos elementos da } \\
\text { AOE }\end{array}$} \\
\hline DIAS, 2007 & $\begin{array}{l}\text { MOURA, 1992,1996, 2000, } \\
2001\end{array}$ & & \\
\hline
\end{tabular}

Fonte: dados dos autores. 
A seguir destacaremos a AOE no processo de produção e análise dos dados das pesquisas selecionadas.

\subsection{A AOE na produção de dados}

Como se observa no Quadro 1, as pesquisas analisadas apresentam diferentes contextos de realização. Dentre esses contextos destacam-se os espaços formativos previamente organizados, independentes da pesquisa (Clube de Matemática e Projeto do Observatório da Educação) e os que foram organizados e direcionados para os procedimentos da pesquisa (Oficina Pedagógica e demais cursos de extensão e atualização).

O Clube de Matemática é um projeto organizado para o desenvolvimento de horas do estágio dos estudantes do curso de Pedagogia e de licenciatura da Universidade de São Paulo. Este projeto se estrutura a partir dos princípios da AOE. Sua organização prevê, em cada semestre, momentos de planejamento das ações de ensino pelos estagiários, momentos de desenvolvimento das ações planejadas com os estudantes das séries iniciais da Escola de Aplicação da USP e momentos de relatos e avaliação das ações desenvolvidas. Dentre as pesquisas aqui analisadas três dissertações e uma tese foram desenvolvidas neste espaço adotando a AOE como princípio de formação (BARROS, 2007; RITZMANN, 2009; VACCAS, 2012; FURLANETTO, 2013). Neste caso, a AOE exerce influência no próprio processo de produção dos dados e é considerada como princípio formador do professor.

O projeto "Educação matemática nos anos iniciais do Ensino Fundamental: Princípios e práticas da organização do ensino", vinculado ao Programa Observatório da Educação (OBEDUC/CAPES), foi desenvolvido por uma rede acadêmica formada por um grupo de professores/pesquisadores que se organizaram em quatro núcleos de investigação. Cada um deles, partindo da intencionalidade de aproximar a universidade (pós-graduação e graduação) das escolas de educação básica, organizou-se em grupos colaborativos que envolveram professores e/ou coordenadores pedagógicos de escolas públicas, alunos da graduação e da pósgraduação e professores universitários. Constituiu-se a partir dos princípios da AOE, cuja dinâmica foi orientadora para o desenvolvimento de duas teses: Araújo (2015) e Gladcheff (2015). 
Tanto no Clube de Matemática quanto no Projeto vinculado ao Observatório da Educação, os pesquisadores tiveram a possibilidade de coletar dados em um espaço formativo que já estava previamente organizado segundo os princípios da $\mathrm{AOE}$.

No caso da Oficina Pedagógica de Matemática e dos cursos de atualização organizados em algumas pesquisas, estes configuraram-se como espaços para coleta de dados, intencionalmente organizados como espaços formativos considerando as necessidades e objetivos das pesquisas. Conforme Moraes (2008), a Oficina Pedagógica de Matemática (OPM), em sua dinâmica formativa, visa a formação teórica dos participantes e constitui-se como espaço para pesquisa, sendo um lugar privilegiado para investigar o processo de pensamento teórico do professor no movimento de elaboração, aplicação, análise e síntese da AOE. Tanto a OPM quanto os cursos citados articulam e unem objetivos formativos e objetivos de pesquisa. Incluímos neste contexto as pesquisas de Moretti (2007), Silva (2008), Migueis (2010), Dias (2007) e Panossian (2013), que nos permitem identificar as possibilidades metodológicas da AOE como orientadora de ações de formação na produção de dados.

A pesquisa de Silva (2008) revela que a AOE é adotada como um caminho para o processo formativo em um curso para educadoras sobre matemática na infância e é tomada como elemento fundamental para a concretização do currículo de matemática na infância. Segundo o autor:

Em nossa investigação, são as manifestações dos diferentes educadores envolvidos, em diferentes contextos, ao agirem com o objetivo de organizar o ensino, que serão objeto de análise. E desta análise serão extraídos elementos indicadores que destacam o processo formativo do educador enquanto estão construindo o que estamos chamando de construção colaborativa do currículo de matemática para educação infantil. (SILVA, 2008, p. 57).

De modo semelhante, a investigação desenvolvida por Migueis (2010) explicita a AOE como metodologia de formação ao esclarecer que:

Este projecto e a dissertação de mestrado foram o ponto de partida para a realização de um trabalho de investigação sobre a actividade de aprendizagem docente num processo de formação de educadores de infância que privilegiou, como metodologia de formação, a atividade orientadora de ensino. (MIGUEIS, 2010, p. 20).

Moretti (2007) explica que AOE pode constituir-se como fundamento teóricometodológico que subsidie a formação de professores aliando teoria e prática com vistas à transformação da realidade escolar e da qualidade de ensino. 
Entendendo o conceito de atividade, dentro dos referenciais teóricos que nos fundamentam, com um caráter específico que, de nenhuma forma, se identifica apenas com a ideia de ação, buscamos no conceito de atividade orientadora de ensino recursos metodológicos que contribuíssem para o processo de formação docente objetivando uma perspectiva de formação não alienante na qual os sujeitos professores se apropriassem do objeto de seu trabalho. (MORETTI, 2007, p. 16).

Por sua vez, é interessante destacar que em sua tese, Dias (2007) observa que o próprio objetivo da investigação desencadeou a AOE e afirma

Compreender o processo de formação da imagem conceitual da reta real em relação com o desenvolvimento desse conceito na perspectiva lógico-histórica, na interação indivíduo coletividade, objetivo dessa investigação, desencadeou uma atividade: a atividade orientadora de ensino. Esta, como particular da atividade humana, procura atender aos princípios da teoria da atividade, tendo como objeto a organização do ensino que, no caso de nossa pesquisa, teve como uma de suas ações a realização de um curso com a intencionalidade de promover o movimento conceitual no compartilhamento de significados. (DIAS, 2007, p. 10-11).

E no caso de Panossian (2013), a AOE desenvolvida no trabalho com os professores possibilitou concretizar a relação entre o movimento histórico e lógico dos conceitos e o objeto de ensino da álgebra, tema que estava sendo investigado.

Num contexto diferente dos anteriormente citados, Cedro (2008) e Ribeiro (2011) têm como espaço formativo a disciplina de Estágio Supervisionado na formação inicial em cursos de Licenciatura em Matemática.

No trabalho de Cedro, a AOE situa-se vinculada à organização de um experimento formativo junto aos estudantes em formação na disciplina de estágio, que segundo o pesquisador intenta:

propiciar aos futuros professores situações em que eles pudessem apropriar-se de uma proposta de organização do ensino. Não uma situação qualquer, mas uma em que fosse possível a aprendizagem sobre o desenvolvimento da atividade pedagógica em uma classe, bem como as reflexões sobre a suas ações como docente: a proposição de situações-problema; a escolha dos instrumentos de mediação; o planejamento de situações de interação entre os indivíduos da sala de aula; o registro da atividade docente de modo a permitir um retrospecto das ações em busca do aprimoramento do seu fazer pedagógico. (CEDRO, 2008, p. 107).

A partir do conceito de AOE, Cedro (2008) entende a noção de espaços de aprendizagem como "o lugar da realização da aprendizagem dos sujeitos orientado pela ação intencional de 
quem ensina" (p. 34). Dessa forma, eles se tornam espaços caracterizados pela crítica, pela descoberta e pela prática social.

Ribeiro (2011) assume a AOE como mediação entre a atividade de ensino e a atividade de aprendizagem. Embora a autora não tenha na AOE lugar central como dinamizadora do processo investigativo, tem na sua compreensão os elementos constitutivos da organização do ensino. Segundo a pesquisadora:

cabe ressaltar a potencialidade da Atividade Orientadora de Ensino como mediadora da organização do ensino na formação de professores, considerando-se os próprios elementos que a constituem, desenvolvida sobre as bases dos elementos da atividade (necessidades, motivos, objetivos, ações e operações), cujo conteúdo principal é o conhecimento teórico e seu objeto é a constituição do pensamento teórico no movimento de apropriação do conhecimento. (RIBEIRO, 2011, p. 77).

Ribeiro (2011) destaca a potencialidade da AOE como referencial para a formação de professores, dadas algumas de suas características principais tais como intencionalidade na ação educativa, atividade como coletividade educativa, situação desencadeadora com o objetivo de aproximar sujeitos de um determinado conteúdo. Tais elementos ancoraram momentos de sua intervenção durante a pesquisa de campo realizada.

Cumpre destacar que a presença da AOE nos processos de coleta e produção dos dados de pesquisa revela como seus princípios constitutivos, relacionados aos elementos da atividade, são mediadores na organização do ensino para a formação dos professores.

\subsection{A AOE na análise dos dados}

A partir da análise das pesquisas selecionadas é possível afirmarmos que os pressupostos da AOE e os elementos que a constituem subsidiaram o processo de análise de dados de forma geral e, em particular, possibilitaram a construção de categorias ou unidades de análise, como descrevemos a seguir.

A análise desenvolvida na pesquisa de Cedro (2008) acompanhou a "elaboração de situações-problema pelos estagiários” (p.146). Na análise dos dados, o autor considera elementos da AOE ao acompanhar ações dos estudantes que revelem transformação e/ou criação dos motivos na atividade de aprendizagem. Entre esses elementos podemos destacar a importância do trabalho coletivo e do compartilhamento de ações na atividade de ensino; 
importância dos nexos conceituais na elaboração de situações-problema; a intencionalidade e o caráter orientador do planejamento e da organização do ensino.

O conceito de AOE também orientou a análise de dados na pesquisa de Ribeiro (2011), que foram organizados a partir de três isolados: Reflexão, Análise e Planificação de Ações. Com base nessa organização, a autora considera os elementos constitutivos da AOE como forma de acompanhar a apropriação do modo geral de organizar o ensino, em especial, no tocante à intencionalidade pedagógica, os motivos e objetivos na proposição de situações desencadeadoras de aprendizagem, ações e operações relacionadas à compreensão do objeto de estudo.

Em sua pesquisa, Ritzmann (2009) analisa seus dados por meio de episódios de ensino, organizados a partir de quatro elementos interdependentes e constituintes da AOE: I. A consciência do papel do jogo e sua intencionalidade; II. O conceito a ser desenvolvido; III. Ações didáticas nas atividades de ensino; IV. O processo avaliativo presente nas diferentes fases em que a atividade está se desenvolvendo. Tais elementos permitiram-lhe evidenciar os aspectos essenciais e determinantes do objeto de sua investigação.

A pesquisa de Gladcheff (2015) evidencia como os professores se mobilizaram e agiram ao organizarem o ensino de matemática, orientados pelos fundamentos teóricos da $\mathrm{AOE}$, tendo como elementos essenciais o conhecimento teórico matemático e a intencionalidade pedagógica no planejamento das ações de ensino. Os dados obtidos foram organizados na forma de episódios de formação e o foco da análise centrou-se nas ações organizadas e praticadas no projeto de formação. Tais ações incidiram também nas escolas, por meio dos professores que delas faziam parte.

Na pesquisa de Araújo (2015), a AOE foi abordada como meio para a elaboração e desenvolvimento de atividades pelos professores participantes do espaço formativo, sendo utilizada como metodologia de formação, pois auxiliou no processo de apreensão e captação do fenômeno investigado. Nessa pesquisa, a AOE não representou apenas um instrumento de ensino. Constituiu-se, também, em um instrumento de investigação, de produção de dados e como possibilidade de levar o professor a refletir, a indagar, a levantar hipóteses e a procurar soluções para os problemas desencadeadores apresentados.

Para atingir seu objetivo, Dias (2007) reconhece a AOE tanto como possibilidade para a organização do curso e coleta dos dados como uma unidade didática específica, no caso a 
Atividade Orientadora de Ensino da reta real onde tem condições de analisar como os professores por meio de suas propostas conceituam a reta real.

Moretti (2007) focou sua análise nas categorias ação, mediação e instrumentos, que entendeu como centrais dentro do referencial teórico assumido. Em um primeiro momento buscou confrontar como as categorias apareceram nos materiais escritos produzidos pelos professores. Em segundo lugar, utilizou a transcrição das gravações feitas em áudio das discussões e socializações que os professores fizeram dos materiais produzidos procurando momentos que revelassem como as mediações feitas em situação coletiva foram apropriadas pelos professores em seus discursos e planos de ação. Para isso, utilizou a ideia de episódios proposta por Moura (1992; 2004).

O modo como as pesquisas citadas organizaram suas categorias/unidades de análise de dados nos permitem identificar a AOE como um fundamento teórico-metodológico de desenvolvimento de pesquisa em educação.

\section{CONSIDERAÇÕES FINAIS}

Este artigo foi conduzido com o objetivo de analisar o papel da AOE no desenvolvimento de pesquisas em espaços formativos que têm como foco o professor que ensina matemática. Nesse sentido, buscou-se reconhecer o referencial teórico-metodológico no qual as pesquisas selecionadas se apoiam, no caso, a Teoria da Atividade, de forma específica, a própria Atividade Orientadora de Ensino.

Observou-se que nestas pesquisas o referencial teórico-metodológico, a organização do processo de coleta de dados e das análises constituem uma unidade cuja articulação tem como eixo central a AOE. Em relação ao processo de produção e coleta dos dados, percebe-se que, ainda que todas as pesquisas tenham sido realizadas em espaços formativos onde estiveram vigentes os princípios da $\mathrm{AOE}$, em algumas delas os espaços foram organizados de modo intencional para a produção dos dados e, desta forma, os objetivos da pesquisa estavam relacionados à organização do espaço formativo.

Já em relação ao processo de análise de dados, identificaram-se pesquisas em que a AOE e seus elementos fundamentaram os processos de análise ou de forma mais específica possibilitaram a construção de categorias ou unidades de análise dos dados da pesquisa. 
Foi possível observar os aspectos do processo formativo dos sujeitos envolvidos (formação de professores) em todas as pesquisas. Nesse sentido, há que se ter o cuidado, também observado em várias pesquisas, de reconhecer os elementos da formação e os elementos que analisam esta formação. Assim, encontram-se argumentos no sentido de que a AOE, em sua origem, sistematizada para a promoção e articulação dos processos de ensino e aprendizagem, também pode ser sistematizada no sentido da pesquisa.

Finalizando, destaca-se que tomar a Atividade Orientadora de Ensino como fundamento teórico-metodológico para o desenvolvimento de pesquisas em educação, em especial as que têm como o foco o professor, implica em investigar modos de compreender o fenômeno educação em movimento, tendo como meta a compreensão acerca da organização do trabalho do professor visando uma educação humanizadora.

\section{REFERÊNCIAS}

ARAÚJO, Neuton Alves de. O professor em atividade de aprendizagem de conceitos matemáticos. Tese (Doutorado) - Faculdade de Educação, Universidade de São Paulo, São Paulo, 2015. 188 p.

BARROS, Luciana Alvares Paes. Desenvolvimento do conceito de avaliação na formação inicial de professores em atividade colaborativa. Dissertação - Mestrado em Educação. São Paulo, 2007.

CARAÇA, Bento de Jesus. Conceitos Fundamentais da Matemática. 9.ed. Lisboa: Livraria Sá da Costa Editora, 1989.

CEDRO, Wellington Lima. O motivo e a atividade de aprendizagem do professor de Matemática: uma perspectiva histórico-cultural. 2008. 242 p. Tese (Doutorado) - Faculdade de Educação, Universidade de São Paulo, São Paulo, 2008.

DIAS, Marisa da Silva. Formação da imagem conceitual da reta real: um estudo do desenvolvimento do conceito na perspectiva lógico-histórica. 2007. 252 p. Tese (Doutorado) Faculdade de Educação, Universidade de São Paulo, São Paulo, 2007.

FURLANETTO, Flávio Rodrigo. O movimento de mudança de sentido pessoal na formação inicial do professor. 2013.194 p. Tese (Doutorado) - Faculdade de Educação, Universidade de São Paulo, São Paulo, 2013. 
GLADCHEFF, Ana Paula. Ações de estudo em atividade de formação de professores que ensinam matemática nos anos iniciais. 2015. 287 p. Tese (Doutorado) - Faculdade de Educação, Universidade de São Paulo, São Paulo, 2015.

LANNER DE MOURA. Anna Regina; SOUSA, Maria do Carmo. O lógico-histórico da álgebra não simbólica: dois olhares diferentes. Zetetiké - Faculdade de Educação, UNICAMP, Campinas, SP, v. 13, n.24, p.11-45, 2005.

LANNER DE MOURA, Anna Regina \& MOURA, Manoel Oriosvaldo. Matemática na Educação infantil: Conhecer, (Re) Criar-Um Modo de lidar com as dimensões do mundo. Escola: um espaço cultural, Diadema, São Paulo, v. 01, n. 01. pp. 1-25, 1996.

LEONTIEV, Alexis. N. O desenvolvimento do psiquismo. Lisboa: Livros Horizonte, 1978.

. Actividad, conciencia, personalidad. La Habana: Editorial Pueblo y Educación, 1983. $2^{\mathrm{a}}$ reimpressão.

Uma contribuição à teoria de desenvolvimento da psique infantil. In: VYGOTSKY, L. S. et al. Linguagem, desenvolvimento e aprendizagem. Tradução Maria da Penha Villa Lobos. São Paulo: Ícone, 2001.

MARCO, Fabiana Fiorezi.; MOURA, Manoel Oriosvaldo de. Quando ações desenvolvidas por professores em processo de formação se constituem em atividade orientadora de formação docente: alguns indiciadores. In: LOPES, A. R. L. V.; ARAÚJO, E. S.; MARCO, F. F. (Org.). Professores e futuros professores em atividade de formação. 1 ed. Campinas: Pontes Editores, 2016, v. 1, p. 19-39.

MIGUEIS, Marlene da Rocha. A formação como atividade de aprendizagem docente. 2010. 263 p. Tese (Doutorado) - Departamento de Ciências da Educação, Universidade de Aveiro, Portugal, 2010.

MOLON, Susana Inês. Questões metodológicas de pesquisa na abordagem sócio-histórica. Informática na Educação, v.11, n.1, p.56-98, 2008.

MORAES, Sílvia Pereira Gonzaga de. Avaliação do processo de ensino e aprendizagem em Matemática: Contribuições da teoria histórico-cultural. Tese (Doutorado) - Faculdade de Educação. Universidade de São Paulo, São Paulo, 2008. 
MORETTI, Vanessa Dias. Professores de matemática em atividade de ensino: uma perspectiva histórico-cultural para a formação docente.2007. 207 p. Tese (Doutorado) - Faculdade de Educação, Universidade de São Paulo, São Paulo, 2007.

MOURA, Manoel Oriosvaldo de. A construção do signo numérico em situação de ensino. 1992, 151 f. Tese (Doutorado em Educação: Ensino de Ciências e Matemática) - Universidade de São Paulo, São Paulo, 1992.

1996.

. A atividade de ensino como unidade formadora. Bolema, Ano II, n. 12. p. 29-43, . (Coord.). Controle da variação de quantidades: Atividades de ensino. São Paulo, FEUSP, 1996a.

. A educação escolar como atividade. In: Encontro Nacional de Didática e Prática de Ensino, 9, 1998, Águas de Lindóia, MG, Anais... Águas de Lindóia, MG, 1998.

(org). O estágio na formação compartilhada do professor: retratos de uma experiência. São Paulo: FEUSP, 1999.

. O educador matemático na coletividade de formação: uma experiência com a escola pública. 2000. Tese (Livre Docência em Educação) - Universidade de São Paulo, São Paulo, 2000.

. A atividade de ensino como ação formadora. In: CASTRO, A. D.; CARVALHO, A. M. P. (Orgs.). Ensinar a ensinar: São Paulo: Pioneira, 2001.

. (Coord.) Organizando a contagem em sistemas. Programa de Formação Continuada. São Paulo: Fundação de Apoio à Faculdade de Educação/USP: 2003.

. Pesquisa colaborativa: um foco na ação formadora. In: BARBOSA, R (org.). Concepções e práticas em formação de professores-diferentes olhares. Rio de Janeiro: DP\&A, 2004.

2010.

. (Org.) A atividade pedagógica na teoria histórico-cultural. Brasília: Liber Livro, 
PANOSSIAN, Maria Lucia. O movimento histórico e lógico dos conceitos algébricos como princípio para constituição do objeto de ensino da álgebra. 2013. 317 p. Tese (Doutorado) Faculdade de Educação, Universidade de São Paulo, São Paulo, 2013.

RIBEIRO, Flávia Dias. A aprendizagem da docência na prática de ensino e no estágio: contribuições da teoria da atividade. 2011. 196 p. Tese (Doutorado) - Faculdade de Educação, Universidade de São Paulo, São Paulo, 2011.

RITZMANN, Camilla Duarte Schiavo. O jogo na atividade de ensino: um estudo das ações didáticas de professores em formação inicial. 2008, 191 p. Dissertação (Mestrado) - Faculdade de Educação, Universidade de São Paulo, São Paulo, 2009

SILVA, Silem S. Matemática na infância: uma construção, diferentes olhares. 2008, 234 p. Dissertação (Mestrado) - Faculdade de Educação, Universidade de São Paulo, São Paulo, 2008.

VACCAS, Amanda Arajs Marques, O planejamento como ação educativa na atividade pedagógica. 2012. 249f. Dissertação (mestrado) - Faculdade de Educação, Universidade de São Paulo, São Paulo, 2012.

Data de recebimento: $18 / 07 / 2017$

Data de aceite: $26 / 10 / 2017$ 